\title{
Electrochemical Oxidation Process to the Degradation of Aqueous Solution Dyes
}

\author{
Fadila Louafi ${ }^{1}$, Ouarda Brahmia ${ }^{2}$
}

\begin{abstract}
In this study, the electrochemical decolourisation of Water textile dyes on $\mathrm{Pt}$ electrodes was assessed. The results demonstrate from one hand, a partial pollutant degradation reaching a maximum of $40 \%$ in the case of Methyl orange in direct oxidation.
\end{abstract}

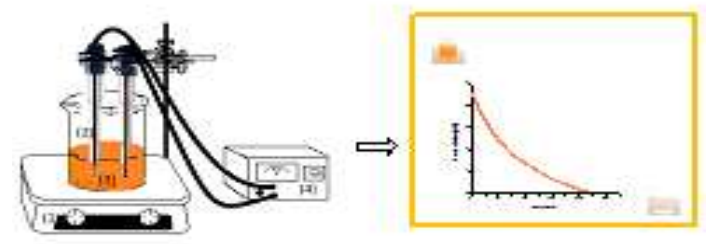

On the other hand, the electrochemical process with the cobalt redox mediator $(\mathrm{Co} 2+/ 3+)$ is able to electrocatalyse efficiently dyes oxidation by shortening significantly the treatment time and enhancing clearly the dye decolourisation rate. Nearly complete decolourisation was achieved. The most striking results achieved with the cyclic voltammetry study demonstrate undoubtedly the product mineralisation. Electrochemical experiments were performed using the spectrophotometric method which is very convenient, easy and allows monitoring the spectral changes as well as the determination of the dye concentration during the process. The kinetics data shows first-order kinetics in the case of the indirect oxidation. A mechanism was advanced to explain the different phenomenon during the electrochemical process.

Keywords-Decolourisation, Textile Dyes, catalyst, Platinum, cobalt, Mediated electrochemical oxidation, mineralisation, cyclic voltammetry.

\section{INTRODUCTION}

Wastewaters originated from various industry such as textile contain various pollutants including a high content of organic matter and suspended masses and dissolved salts [1, 2]. Moreover, organic dyes used to dye cotton, acrylic, silk and wood are considered as widespread environmental pollutants. [3] In the case of textile industry, up to $50 \%$ of the synthetic dyes with different structural varieties such as; azo, diazo, quinine imine, thiazole and others [4] are lost after the dyeing process and disposal out of the effluents [5]. Therefore, their elimination from wastewaters is an obligation to prevent the ecosystem destruction. Conventional wastewater treatment based on the biological process is not suitably enough to

\footnotetext{
${ }^{1}$ UR CHEMS, Frères Mentouri Constantine University, Algeria.

${ }^{2}$ Laboratoire des techniques innovantes et de preservation de l'environnement, Frères Mentouri Constantine University, Algeria..
}

remove recalcitrant dyes from effluents [6]. Physical and chemical methods used for eliminating dyes (i.e. adsorption, incineration, electrocoagulation, photocatalysis, ozonation and others) are reasonably effective but relatively cost [7, 8]. That's why; it's necessary to find an effective wastewater method capable of degrading toxic organic compounds from industrial effluents. As an alternative, the electrochemical oxidation process is a clean advanced oxidation technology because the main reagent; the electron, is a clean one [9]; it was applied successfully and proved to be convenient and fruitful to destruct bio-refractory organic compounds due to its high effectiveness and environment well-suited. In the electrochemical oxidation under room temperature and atmospheric pressure, generally, researchers focus their particular interest on the anode oxidation process than the cathode reduction. One alternative to efficiently remove color from solutions of structurally different dyes (methyl orange, phenol red, crystal violet, bromophenol blue, fuchsin, and poly R-478) is provided by Mediated Electrochemical Oxidation (MEO) with Co(III) [10]. In this context, we accomplish the MB [11], CR electrochemical degradation in the presence of $\mathrm{Co} 2+/ 3+$ selected as a redox mediator using Pt electrodes. Moreover, it is noteworthy the conductor behavior of MO, MG and CR that's why we achieved this study without a supporting electrolyte to test the feasibility of dyes electrochemical degradation. It should be noted as well that generally dyes are susceptible to undergo a photochemical degradation as they absorb in the visible part of the electromagnetic spectrum, that's why we have worked in the obscurity to avoid any probability of a possible photodegradation pathway. The aim of this work is to test the feasibility of the electrodegradation of $\mathrm{MO}, \mathrm{MG}$ and $\mathrm{CR}$ in our particular conditions. The decolourisation rate has been evaluated with and without the redox mediator and the mechanism of the process was as well suggested in both direct and indirect oxidation.

\section{EXPERIMENTAL SECTION}

\section{A. Materials}

Methyl orange (MO), Congo red (CR) and Methyl green (MG) was purchased from Labosi (for analysis) and used without further purification. The cobalt chloride $(\mathrm{CoCl} 2,6$ $\mathrm{H} 2 \mathrm{O}$ ) used as redox mediator was purchased from Biochem. Solutions were prepared using distilled water.

\section{B. Methods summary}

The electrochemical process was carried out using the spectrophotometric method to follow the dyes decolourization. 
The study was conducted on the aqueous solution of MO, CR and $\mathrm{MG}$, under atmospheric pressure, at room temperature, and in the obscurity. Experiments were carried out in an electrochemical cell containing the amount of $25 \mathrm{ml}$ of dyes for each experiment and using electrodes placed in the cell center with a distance of $2 \mathrm{~cm}$ separating them. The anode and cathode are $\mathrm{Pt}$ wire from Voltalab. The ratio electrode surface/volume of dye solution was $0.04 \mathrm{~m} 2 . \mathrm{m}-3$ at laboratory scale. A constant voltage drop of 5 Volt was applied to the electrodes using Potentiostat (Alimentatore per elettroforsi el VI 16, Italy). The reaction vessel was placed on a magnetic stirrer for continuous stirring to ensure the solution homogeneity during the electrochemical process. The conductivity of the initial dyes solution was measured by a conduct-meter model (Inolab Cond 7110) and diverse chromophoric groups of highly unbiodegradable and recalcitrant characteristics were in table1. According to this conductor behavior, we choose to perform our experiments without any electrolytes and test the feasibility of Methyl orange, Congo red and Methyl green degradation in this condition. During the electrochemical process, after each treatment time, we transfer the solution to the UV-visible spectrophotometer (Jenway 6505) to record the absorption spectra of the dye solution and to measure the absorbance at the maximum absorbance using a matched pair of quartz flows cells $(1 \mathrm{~cm}$ path length). The absorbance data were converted

TABLE 1 : PRINCIPAL PARAMETERS OF USED DYES

\begin{tabular}{|c|c|c|c|}
\hline Name & Methyl orange & Congo red & Methyl green \\
\hline Class & Azo & Azo & Triphenylmethane \\
\hline Formule brute & $\mathrm{C}_{14} \mathrm{H}_{14} \mathrm{~N}_{3} \mathrm{O}_{3} \mathrm{~S}$ & $\underline{\mathrm{C}}_{32} \underline{\mathrm{H}}_{22} \underline{\mathrm{N}}_{6} \underline{\mathrm{Na}}_{2} \underline{\mathrm{O}}_{6} \underline{\mathrm{S}}_{2}$ & $\mathrm{C}_{26} \mathrm{H}_{33} \mathrm{Cl}_{2} \mathrm{~N}_{3}, \mathrm{ZnCl}_{2}$ \\
\hline $\begin{array}{l}\text { Chemical } \\
\text { Structure }\end{array}$ & & & $\mathrm{H}_{3} \mathrm{C}^{\mathrm{N}} \mathrm{C} \mathrm{CH}_{3}$ \\
\hline $\begin{array}{c}\text { Molecular } \\
\text { weight }(\mathrm{g} / \mathrm{mol})\end{array}$ & 696,663 & 696.66 & 594,80 \\
\hline$\lambda \max (\mathrm{nm})$ & 470 & 500 & 635 \\
\hline pH & 8.39 & 8.79 & 7.34 \\
\hline $\begin{array}{c}\text { Conductivity } \\
(\square \mathbf{S} / \mathbf{c m})\end{array}$ & 110 & 210 & 110 \\
\hline
\end{tabular}

\section{RESULTS AND DISCUSSION}

\section{A. Direct monocomponent oxidation of $M O, C R$ and $M G$}

\section{Decolourisation rate}

To assess the feasibility of the electrochemical process conducted on a solutions dyes $(45 \square \square \mathrm{M})$ at initial basic $\mathrm{pH}$, we experimentally followed the decolourisation by measuring the dye absorbance at its absorption maximum as a function of the different electrochemical treatment time. The decolourisation expressed in terms of percentage was calculated according to equation (1). The obtained results are shown in figure (1). to the concentration using Beer-Lambert equation (1). $\mathrm{A}=\square$. C. L (1), where A and $\square$ are respectively the absorbance and molar absorptivity coefficient values at the maximum absorbance wavelength of each dye, $\mathrm{C}$ is the dye concentration at time $t, 1$ is the light path length. The value of $\square \square$ at maximum absorbance wavelength was deduced from the dyes calibration curve. The assays were done twice; the experimental error was below $3 \%$. The decolourisation rate of the dye was expressed as a percentage and calculated by the following equation (2); \% dye decolourisation $=[(\mathrm{C} 0-\mathrm{Ct}) /$ $\mathrm{C} 0] \times 100 \quad(2)$, where $\mathrm{C} 0$ and $\mathrm{Ct}$ are the dye concentrations at time 0 and time $t$ respectively. The concentration of the dye was calculated from the absorbance value at maximum absorbance wavelength using a calibration curve. Voltammetric experiments were carried out with a potentiostat model Gamry (USA). The working electrode was a platinum electrode and a reference electrode was a saturated calomel electrode (SCE). All potentials were reported vs. the SCE. A platinum electrode was used as the counter electrode. The scan rate was $100 \mathrm{mV} / \mathrm{s}$. The experiments were achieved using a cell of $20 \mathrm{ml}$, we purged the dissolved oxygen by nitrogen bubbling during 25 minutes and we used as $0.1 \mathrm{M}$ of $\mathrm{KCl}$ as supporting electrolyte. 
reached a maximum of $47 \%$. For a treatment time of 250 minutes, the decolourisation percentage does not change; this leads us thinking about an inhibitory effect on the elimination of MO due probably for its aromatic structure

\section{Electro-degradation kinetics}

To better understand the pollutant behavior, we convert the absorbance to concentration and plotted the kinetics of the pollutant disappearance (figure 2).

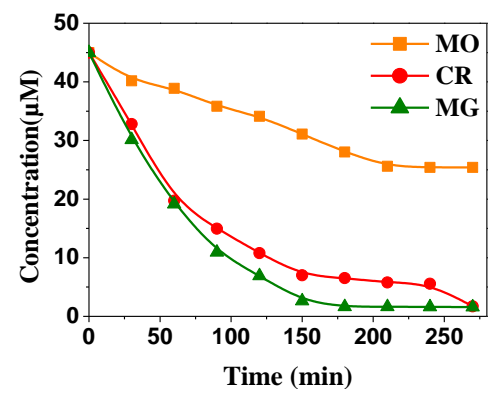

Fig. 2 : Direct electrochemical decolourisation of MG, CR and MO.

According to the plotted curve, it appears two different phases, the first one corresponds to a treatment time between 0 and 150 minutes, the elimination rate is rapid at the beginning of the reaction. During this time period, we can readily admit that the reaction proceeds most probably by a transfer of electrons. On one hand, the pollutant undergoes anodic oxidation since it is capable of giving electrons especially those of the lone doublets of sulfur and nitrogen atoms. On the other hand, we admit a cathodic reduction of water; this last lead to the formation of $\mathrm{OH}^{-}$anions with the release of $\mathrm{H}_{2}$ according to the reaction (1): $2 \mathrm{H}_{2} \mathrm{O}+2 \mathrm{e}^{-} \rightarrow 2 \mathrm{OH}^{-}+\mathrm{H}_{2}$ (1)

We can summarize the mechanism of electro-degradation according to the following scheme (where $P$ and $P^{+}$are respectively the pollutant and the oxidized pollutant).

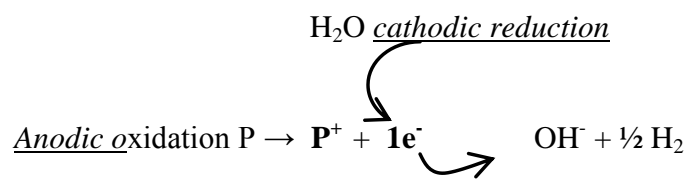

Scheme 1: Mechanism of dyes direct oxidation

The second part of the curve is included between 210 and 250 minutes, we stopped at this end because the electrodegradation rate no longer changes. This strongly suggests that the intermediates formed during the reaction can compete with the pollutant itself and thus inhibit its elimination. We can generally accept that reactions consuming electrons can limit the dyes direct oxidation in solution. All this goes to prove that the direct electrochemical oxidation is capable of oxidizing just partially the MO solution, that's why it's interesting to optimize this process to reach the dye total degradation.

The decolourisation kinetics can be quantitatively described as the first order with respect to the dye concentration. The rate values and the statistical correlation parameter are shown in table2.
TABLE II : KINETICS COEFFICIENTS FOR A FIRST ORDER ELECTRO

\begin{tabular}{ccc}
\multicolumn{3}{c}{ DEGRADATION REACTION OF DYES } \\
\hline Dye & $\mathbf{k}\left(\mathbf{x ~ 1 0} \mathbf{~ 1 0}^{-3}\right)\left(\mathbf{m i n}^{-\mathbf{1}}\right)$ & $\mathbf{R}^{\mathbf{2}}$ \\
\hline Methyl Orange & 1.99 & 0.987 \\
Congo Red & 9.67 & 0.939 \\
Methyl Green & 16.99 & 0.962 \\
\hline
\end{tabular}

The kinetics coefficient indicated the same results decolourisation rate obtained of $\mathrm{MG}, \mathrm{CR}$ and $\mathrm{MO}$.

\section{B. Decolourisation of dyes mixtures}

Real effluents often include more than one component and the study of the possible interactions between different chromophores will be very useful. Here we tested mixture of azo dye (MO) and triphenyl methane dye (MG). The UV/visible spectrum of mixtures of dyes shown in figure 3 . The decolourisation rate of each dye changed when the technique was applied to the mixture. Significant differences on decolourisation rate of MO and MG was observed due to the class of each dye.

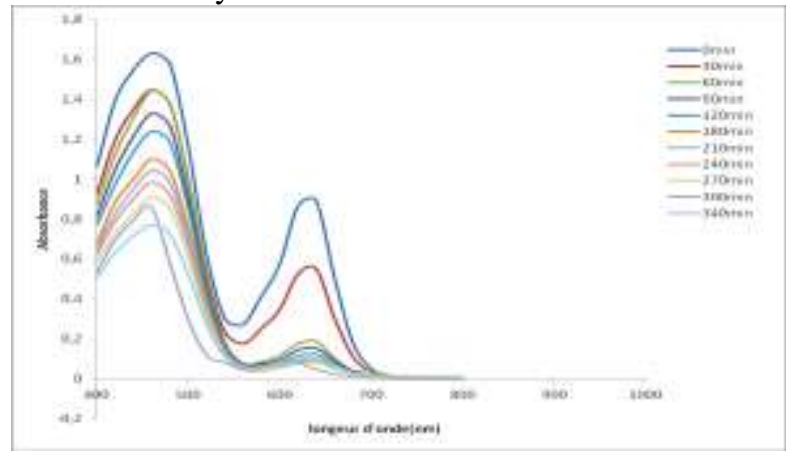

Fig. 3 : Direct electrodecolourisation of dyes mixtures

The Methyl Orange reached decolourisation percentage of about $48 \%$ after 240 minutes in monocomponent oxidation and $40 \%$ after the same time. The reached decolourisation rate of about $96 \%$ after 180 minutes of $\mathrm{MG}$ in the monocomponent dye solution, only $84 \%$ was observed in solution mixture. This can explain by the competition between the two dyes at anode electrode.

\section{INDIRECT OXIDATION}

It's well established that the redox mediators such as $\left(\mathrm{Fe}^{2+/ 3+}, \mathrm{Ce}^{3+/ 4+}, \mathrm{Co}^{2+/ 3+}\right)$ are able to generate electrochemically oxidizing species capable of inducing degradation of dyes [12]. Therefore, it is interesting to consider the redox catalyst effect on MO oxidation. We started with the couple $\mathrm{Ce}^{3+/ 4+}$ catalyst, no significant change was observed in terms of dye disappearance, this is probably due to its moderate oxidation potential $(1.72 \mathrm{~V})$. The second attempt was performed using the couple $\mathrm{Co}^{2+/ 3+}$ with a slightly higher oxidation potential $(1.92 \mathrm{~V})$ [12]. We tested its effect on MO, CR and MG electro-degradation.

\section{A. Evolution of monocoponent dye solution absorption spectra}

In terms of experimental conditions, the study was performed by adding a solution of $\mathrm{CoCl}_{2}\left(10^{-7} \mathrm{M}\right)$ to the initial dyes solutions $(45 \mu \mathrm{M})$, basic initial $\mathrm{pH}$ using the same platinum electrodes. In figure 5 we presented the percentage of 
dyes decolourisation according to the different treatment time during the indirect oxidation.

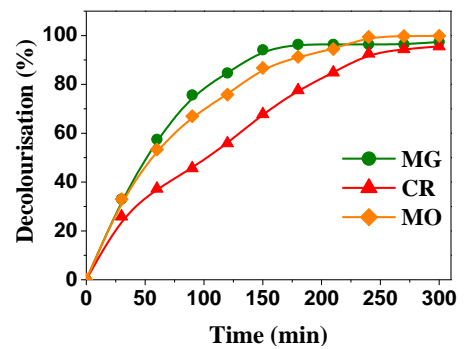

Fig.4: Decolourisation rate of dyes in the presence of $\mathrm{Co}^{2+/ 3+}$ catalyst.

\section{B. Photocatalytic Degradation of $M B$ in aqueous solution} by $\mathrm{TiO} 2 / \mathrm{SL}$ and $\mathrm{ZnO} / \mathrm{SL}$

The most striking result shows that the almost complete dyes decolourisation after 250 minutes against low decolourisation of $\mathrm{MO}$ in the case of the direct oxidation. This reflects the substantial role played by the catalyst in the electrochemical process to increase the dye decolourisation percentage.

These results demonstrate that a small amount of cobalt $\left(10^{-7}\right.$ M) is largely enough to effectively catalyze the electrochemical reaction of dyes. Furthermore, in terms of reaction kinetics, the indirect oxidation is first-order kinetics. The rate constant of the reaction is deduced from the curve representing (ln $\mathrm{C}_{0} / \mathrm{C}$ versus time). The rate constant values and statistical correlation are shown in table3.

TABLE 2 : Kinetics coefficients for a first order electro degradation reaction of dyes in presence of $\mathrm{Co}^{2+}$ mediator

\begin{tabular}{ccc}
\hline Dye $+\mathrm{Co}^{2+}$ & $\mathrm{k}_{1}\left(\mathrm{x}^{2+} 0^{-3}\right)\left(\mathrm{min}^{-1}\right)$ & $\mathrm{R}^{2}$ \\
\hline Methyl Orange $+\mathrm{Co}^{2+}$ & 11.9 & 0.999 \\
Congo Red $+\mathrm{Co}^{2+}$ & 3 & 0.998 \\
Méthyl Green $+\mathrm{Co}^{2+}$ & 10 & 0.995 \\
\hline
\end{tabular}

In this process, metal ions are oxidized anodically from a stable oxidation state to reactive species, which in turn, are capable of oxidizing organic substances to $\mathrm{CO}_{2}$ [10]. The electro-degradation mechanism is presented by the following scheme.

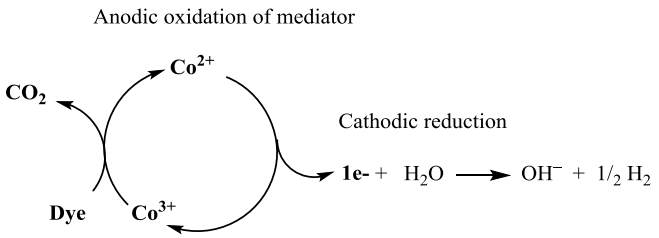

dye oxidation

Scheme 2: Mechanism of dyes oxidation with redox mediator $\mathrm{Co}^{2+}$

Following these results, we can say that the redox mediator acts as a catalyst for the complete decolourisation of methyl orange Figure 4.

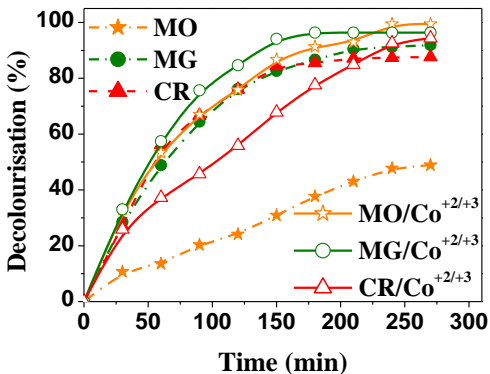

Fig. 5: Comparison between the dyes decolourisation rate (with and without catalyst).

C. Decolourisation of dyes mixtures in the presence of redox mediator

At the same dyes mixtures used above, the $\mathrm{CoCl}_{2}$ solution $\left(10^{-7} \mathrm{M}\right)$ was added to the solution of the initial concentration of $45 \mu \mathrm{M}$ mixture. The evolution of the dyes mixtures of the absorption spectrum for discoloration figure 4 shows a significant difference compared with that found for the direct discoloration figure 3 . The using of redox mediator favors complete degradation of mixtures of dyes into simpler compounds or even reaching a complete mineralization.

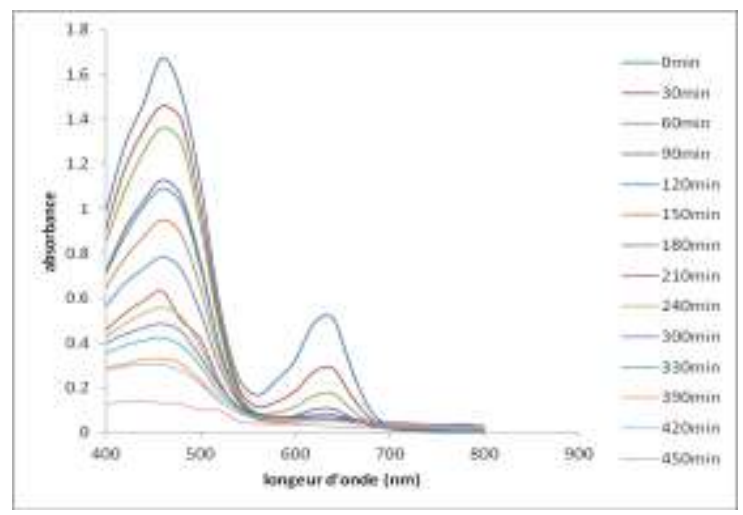

Fig. 6: Indirect electrochemical decolourisration of dyes mixtures in presence of $\mathrm{Co} 2+$

The voltammogram (CV) of free Methyl Green in $\mathrm{KCl}$ on $\mathrm{Pt}$ electrode at scanning rate $100 \mathrm{mVs}^{-1}$ shown the presence of an irreversible oxidation peak at a potential of 1.1 V / SCE and irreversible reduction peak at $-0.4 \mathrm{~V} / \mathrm{SCE}$. After complete discoloration of the dye, the recorded voltammogram shown the disappearance of the oxidation peak, and occurrence of an irreversible reduction peak at a potential of $0.2 \mathrm{~V} / \mathrm{SCE}$ and a reversible system with an anodic peak potential (Epa) to - 0.3 V / SCE and cathodic peak potential (Epc) of - 0.6 V / SCE. The resulting irreversible redox system is probably due to the reduction of $\mathrm{CO}_{2}$ mineralization occurs in the following half reaction: $\mathrm{CO}_{2}+\mathrm{e}^{-} \rightarrow \mathrm{CO}_{2}{ }^{-}$. 


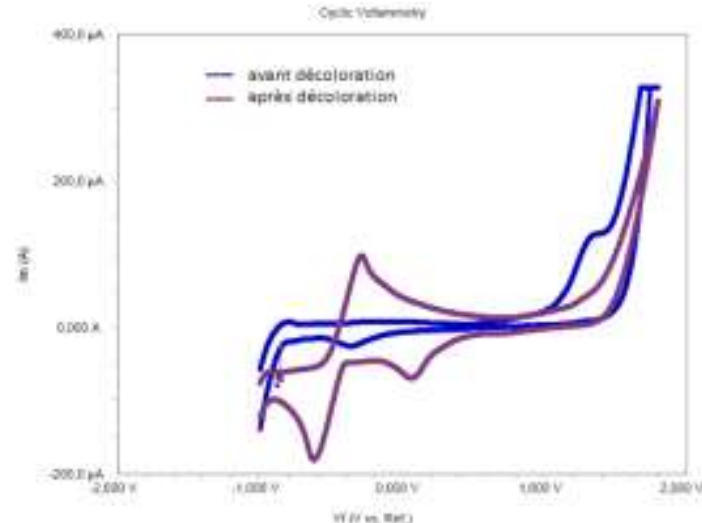

Fig. 7 : Voltamogramm of MG before and after decolourisation

\section{V.CONCLUSION}

The study in this work shows that the electrochemical oxidation process is effective under our experimental conditions for the treatment of wastewaters dyes of azo type and triphenylmethane type. This method allows to eliminate or reduce the quantity of chemical reagents in producing oxidants directly into the medium by electrochemistry. By its environmental compatibility, it is an efficient and clean solution to the objectives of green chemistry and sustainable development. Electrochemical treatment of dye solutions in the presence of the redox mediator $\mathrm{Co}^{2+} / \mathrm{Co}^{3+}$ plays an important role on the speed of electrodegradation the dye and the decolourisation rate.

\section{REFERENCES}

[1] RT. Parry, In: Parry RT editor. Principles and Applications of Modified Atmosphere Packaging of foods. London. Blackie Academic Press: 1993.

https://doi.org/10.1007/978-1-4615-2137-2

[2] http:// en.wikipedia.org/wiki/Methylene Blue

[3] B.H.Hameed, T.W. Lee, Degradation of malachite green in aqueous solution by fenton process, J. Hazard. Mater, 2009:164:468. https://doi.org/10.1016/j.jhazmat.2008.08.018

[4] I. M. Banat, Nigam P, Microbiol decolorization of textile dyes containing effluents: A review, Bioresource. Technology, 1996:58:217. https://doi.org/10.1016/S0960-8524(96)00113-7

[5] Zollinger, Color Chemistry: Syntheses, properties and Applications of Organic Dyes and Pigments. VCH Publishers, Weinheim, Germany: 1991.

[6] G.M. Shaul, T.J. Holdsworth, Dempsey C.R, Dostall K.A, Fate of water soluble azo dyes in the activated sludge process, Chemosphere, 1991:22:107. https://doi.org/10.1016/0045-6535(91)90269-J

[7] C. Zhu, L .Wang, L. Kong, X.Yang, S. Zheng, F. Chen, F. Maizhi, H. Zong, Photocatalytic degradation of AZO dyes by supported $\mathrm{TiO} 2+\mathrm{UV}$ in aqueous solution, Chemosphere, 2000:41: 303. https://doi.org/10.1016/S0045-6535(99)00487-7

[8] L. Szpyrkowicz, C. Juzzolino, S.N. Kaul, A comparative study on oxidation of disperse dyes by electrochemical process, ozone, hypochlorite and Fenton reagent, Water. Res, 2001:35:2129. https://doi.org/10.1016/S0043-1354(00)00487-5

[9] K. Juttner, U. Galla, H. Schmieder, Electrochemical approaches to environmental problems in the process industry, Electrochim. Acta, 2000: 45: 2575 .

https://doi.org/10.1016/S0013-4686(00)00339-X

[10] Sanroman M.A, Pazos M, Ricart M.T, Cameselle C, Electrochemical decolourisation of structurally different dyes, Chemosphere, 2004:57:233

https://doi.org/10.1016/j.chemosphere.2004.06.019
[11] O.Brahmia, F. Louafi Sciences\& Technologie A- $N^{\circ} 42$, Décembre 2015, 9-14.

[12] J. Bringman, K. Ebert, U. Galla, H. Schmieder, Electrochemical mediators for total, oxidation of chlorinated hydrocarbons: formation kinetics of $\mathrm{Ag}$ (II), $\mathrm{Co}(\mathrm{III})$ and $\mathrm{Ce}(\mathrm{IV})$, Journal of applied electrochemistry 